\title{
1922: acercamiento a los contextos y alrededores de Trilce
}

\author{
Diana Rodríguez Sánchez \\ Universidad de Guanajuato
}

Resumen

El presente análisis tiene como finalidad realizar un acercamiento al poemario Trilce, de César Vallejo, a partir de su relación con el contexto y las lecturas próximas a 1922, año de su publicación. En los albores del siglo XX, el hombre moderno cuestiona los discursos impuestos por la lógica y la razón, bajo una tradición que hizo de la metafísica el único camino de conocimiento del ser. Los alrededores a los que se acude son el poema La tierra baldía y enfoques que abordan la crisis del sujeto y la posición radical del lenguaje, con el propósito de ofrecer posibles rutas de lectura acerca del poemario.

Palabras clave: Trilce, La tierra baldia, deconstrucción.

\section{Abstract}

The aim of this analysis is to get a better understanding of the collection of poems Trilce, by César Vallejo, viewing it in relation to the context and writings of its time, about 1922, the year of its publication. At the beginnings of the $20^{\text {th }}$ century, modern man began to question the lessons derived from the logic and reasoning of the metaphysical tradition, at that time the only path to knowledge of being. Trilce will be analysed in light of the following texts and theories: The Waste Land, theories and texts that talk about the crisis of the subject 
and the radical position of language. The purpose of this analysis will be to offer possible routes of reading for the Trilce collection of poems.

Keywords: Trilce, The Waste Land, deconstruction.

G 1922 se publican dos de las obras fundamentales para la literatura: La tierra baldía, de T. S. Eliot, y el Ulises, de Joyce, creaciones que marcan un antes y después, no sólo en la poesía y la novela en lengua inglesa, sino en la tradición universal. En la historia editorial rara vez se dan casos como el antes citado. Se trata de la convergencia de proyectos de escritura que confirman un mecanismo violento en la expresión artística y, por ende, en el mismo lenguaje.

Latinoamérica se une a dichos azares editoriales y en este mismo año, desde Lima, Perú, César Vallejo publica Trilce, poemario que se incorpora a los mecanismos violentos del lenguaje para evidenciar a un sujeto en crisis que muestra su orfandad en un hogar extrínseco: pone en escena la intemperie del ser. Analicemos, entonces, algunos motivos que acercan a las preocupaciones que Vallejo anuncia en su poemario, con la intención de exponer una comparativa a partir de las preocupaciones que resuenan en otros contextos y textos cercanos al año de 1922, tanto literarios como filosóficos; en particular, el cruce de temas en el poema La tierra baldía y planteamientos que abordan la crisis del hombre moderno y la puesta radical del lenguaje para ofrecer posibles rutas de lectura del poemario Trilce.

El hecho de encontrar líneas que trazan uniones poéticas entre contemporáneos, residentes en lugares diversos, permite conocer al hombre de una época, con sus preocupaciones y su relación con determinados hechos históricos que conforman un estado de las cosas, así como al sujeto y su manera de configurarse en la poesía. $\mathrm{Al}$ respecto, M. Heidegger reflexiona sobre el decir proyectante que es poesía, 
el decir del mundo y la tierra, el decir del campo de su lucha, y con ello del lugar de toda cercanía y lejanía de los dioses. La Poesía es el decir de la desocultación del ente. El lenguaje en este caso es el acontecimiento de aquel decir en el que nace históricamente el mundo de un pueblo y la tierra se conserva como lo oculto. [...] En tal decir se acuñan de antemano los conceptos de la esencia de un pueblo histórico, es decir, la pertenencia de éste a la historia universal (2006: 85).

Sobre esta pertenencia versa el interés del análisis, pues veremos cómo dos propuestas poéticas — la de Vallejo y la de Eliot- resuelven, a su manera, los conflictos del hombre moderno y su preocupación por la existencia. Además, no es casual que en la misma década se postulara en El ser y el tiempo (1927) una discusión que desde el ámbito filosófico se unía a la constante de abordar al ser escindido por el lenguaje y su permanencia en el mundo. El devenir del ser en la historia, ese "ser ahí" en un mundo desolado por una primera guerra mundial y diversas guerras civiles, es puesto en "estado de yecto", en el salto irreversible que a Vallejo le cuesta tanto. Las consideraciones del filósofo son aunadas a su disposición sobre el "ser para la muerte", que justifica el miedo y la desolación que trae consigo la conciencia. Quizás es en la "cura" en donde encontramos lo que diferencia a una propuesta poética de la otra, al confrontar un lamento por la permanencia en la tierra baldía en Eliot o un canto por "el placer que nos DestieRRa" (LX, v. I9) en Vallejo.

\section{Sobre los contextos de Trilce}

Según la "Nota filológica preeliminar" a su Obra poética, la producción literaria de César Vallejo fue realizada en un periodo relativamente corto: de 1913 a 1938, desde sus primeras publicaciones 
en una revista trujillana, hasta los poemas que seguía revisando en vísperas de su muerte en París. Vallejo nació en Santiago de Chuco, Perú, en 1892, y fue hasta los venticinco años cuando decidió partir a Lima, lugar donde publicó sus dos primeros poemarios: Los heraldos negros (1919) y Trilce (1922). Un aparente intento de suicidio por motivos amorosos y un ambiente intelectual del que merecía críticas y reproches "lo hacían sentir ya la estrechez del medio trujillano, que debieron apurar su decisión de proseguir sus estudios universitarios en Lima” (1996: 5), apunta José Miguel Oviedo.

Después de la publicación del primer poemario, el rápido acceso y reconocimiento que Vallejo tuvo entre las principales figuras literarias limeñas no se hizo esperar; sin embargo, el "ambiente extraño agudiza en él la tendencia introspectiva y su indagación filosófica por el sentido de la existencia, cuyo símbolo central es, para él, el hogar" (Oviedo, 1996: 5). Primero ocurre la de su amor juvenil de Santiago, luego la de su padre literario, González Prada, e inmediatamente después la de su madre; hechos que marcarían en Vallejo sus obsesiones por la orfandad, los amores muertos y ausentes, la fatalidad. Esta situación lo llevó a regresar dos años más tarde a su lugar natal, donde ocurriría otra experiencia determinante para Trilce: la cárcel. César estuvo preso 112 días a raíz de una participación que absurdamente se le achacó a él y a sus dos hermanos en los disturbios de la asonada en Santiago de Chuco, el 1 de agosto de 1920. La experiencia de la cárcel fue precedida por la angustia de más de dos meses de persecusión y vida clandestina. Como apunta Américo Ferrari en la introducción al poemario: "La evolución de la escritura poética entre 1918 y 1922 tiene, junto con las vivencias dolorosas del poeta en estos ańos, una importancia determinante para el significado y la proyección de Trilce" (2006: 163). 
Por su inminente ruptura con el modernismo y el simbolismo, la publicación del libro en 1922 pasó en total silencio ante la crítica limeña, situación que marcó la recepción de la obra. De cualquier manera, Vallejo había decidido cortar las amarras y viajar a Europa. En 1923 comienza su faceta de viajero, al instalarse en París. En 1930 publica en Madrid una segunda edición corregida de Trilce, la cual señaló el descubrimiento de su poesía en España, donde fue sometida a la lectura y la crítica. Y después de ejercer como profesor, la enfermedad instala al poeta en París, donde muere en 1938.

\section{De sus alrededores: Trilce, de César Vallejo}

Para comprender la visión de Vallejo es necesario considerar temas como la muerte, la madre, el erotismo, la recreación de aspectos biográficos, las influencias del contexto social, cultural y literario, entre muchos más. El poemario surge en el contexto de la crisis moderna, de la imposibilidad del ser para trascender la angustia del presente, una angustia que potencia el deseo vanguardista de una época. El universo para César Vallejo es ilógico, desordenado, caótico, contrario a la razón, pues Trilce surge en el contexto de las vanguardias literarias (1920-1930), momento en que los ismos europeos, tales como el dadaísmo, el surrealismo o el expresionismo, influyeron en las vertientes literarias de Latinoamérica, los cuales ejercieron una influencia importante en su estilo y en su concepción de la realidad.

En Trilce ${ }^{1}$ son 77 los poemas que ponen en escena la crisis del sujeto ante la experiencia del desamparo y la exacerbación vital,

${ }^{1}$ Para el análisis del poemario consideramos como referencia la edición crítica de la Obra poética, de César Vallejo, coordinada por Américo Ferrari, y publicada en 1996 para la Colección Archivos de la UNESCO. Esta publicación contempla dos ediciones de Trilce, la de 1922 y 1930. 
en donde la búsqueda sucede en torno a ese sujeto excéntrico (sin centro), que cuestiona y duda del decir, que ¿Te encontraste esa perrita? Si necesitas paro te coperamos con lo de la cirujía. se revela ante la insuficiencia del lenguaje: "Nombre Nombre. / ¿Qué se llama cuanto heriza nos? / Se llama Lomismo que padece / nombre nombre nombre nombre" (II, vv. 13-16).

Para Vallejo la palabra se convierte en intersticio por donde se produce una fuga de sonoridad y repetición, debido a que la fonética, el significante de la lengua, es incapaz de comunicar, pues sólo imparte consignas desemantizadas, cuyo efecto inmediato se encuentra en un plano de interioridad: acto de rebelión y resistencia. Es un asunto de voluntad sobre el lenguaje que es "Lomismo" y que padece, pero del que también se engendra la plegaria del "nombre", como un llamado a la inmovilidad existencial y, al mismo tiempo, como un obstáculo libertador. Ante la desconfianza del lenguaje es necesario comunicar a través de una búsqueda transgresora, allí donde el entredicho sea más eficaz que el uso lingüístico referencial y carcelario. "Lomismo" es la repuesta que desmantela la relación del tiempo con el hombre; es decir, el fatalismo del tiempo y la historia. En cualquier tiempo aquello que "heriza nos" será lo mismo: presente, pasado y futuro. Se trata de un pronombre personal que vulnera la relación inmediata ante el caso de efecto, y no de causa, síntesis que enfatiza la inmovilidad, la culpa, el padecimiento.

Es en la puesta en crisis del lenguaje donde observamos la ruptura de la gran narración a partir de lo humano. Vallejo nombra, entonces, lo singular, lo anónimo, aquello que en la experiencia de significar es indecible. La desconfianza ante el lenguaje provoca la denuncia de su falsedad en una explosión de dolor y abandono. Tras la salida involuntaria, el ser intenta regresar al estado de inocencia, la recuperación de lo primigenio que dé sentido a la existencia y su finitud, debido al anuncio de que la vida gobernada 
por la muerte no puede ser resistida. Ante esta consideración es evidente que la orfandad ocupa un lugar central en el poemario, un lamento ante la angustia del ser y un enfrentamiento con los límites de la expresión; se trata de un canto a pesar de un mundo fragmentario y hostil, después del salto involuntario que lo aleja del origen, tanto de la madre como del propio lenguaje. Así, Tril$c e$ "se va rompiendo y rearticulando, rompiendo y rearticulando porque el poeta no sólo cumple la función de nombrar las cosas sino también, prioritariamente, la de nombrar, por primera vez, los nombres de las cosas" (Celorio, 1988: 45).

Consecuencia de la angustia generada por el desengańo y la fragmentación, el yo poético hace una pregunta o una demanda que al parecer no tiene respuesta, de manera que la dispersión y la ruptura del lenguaje exponen un alma rota: "Quién hace tanta bulla y ni deja / testar las islas que van quedando. / Un poco más de consideración..." (I, vv. 1-3), consideración de un sujeto desarticulado del mundo que clama un cuestionamiento que le confirme su devenir. En palabras de José Ángel Valente "La brusca aparición de lo mínimo humano y de sus símbolos denuncia la ocultación operada por los grandes lenguajes conceptualizantes, por los decires de la totalidad. Frente a ellos, el hombre se quiebra, se fragmenta, es, en rigor, fragmento, no totalidad" (1996: XXIV). Trilce privilegia el intersticio como zona de estrategia a partir de una escritura que tiene su génesis en una problemática existencial y del lenguaje, donde fluye de la herida el angustiante y tierno canto.

En el primer poema encontramos una declaración de principios sobre su acontecer en la existencia. Inicia el poemario con el arribo a la tierra de un yo poético que cuestiona el estado de las cosas y emite un llamado perturbador: "Quién hace tanta bulla, y ni deja / testar las islas que van quedando" (I, vv. 1-2). Este llamado apela a una respuesta y a la inconformidad de quien ha permanecido hasta ese momento inmóvil, pero que con su habla (bulla) coarta la posi- 
bilidad de afirmar un pasado que daría sentido a su existencia en la tierra. En la recuperación de este pasado, es la "calabrina ${ }^{2}$ tesórea" la que intenta anclar al ser de golpe, donde desafía al fragmento de "cada hialóidea ${ }^{3}$ grupada", como el embate impetuoso y violento de los caminos - o conductos - que transportan la sangre a todo el cuerpo desde "el insular corazón". El tropo náutico no sólo se erige en el "mantillo líquido" de la tierra sino del propio cuerpo humano: agua y sangre, tierra y cuerpo.

Además, para enfatizar el llamado que también es música (y no bulla) que proviene del impetuoso mar: "DE LOS MÁS SOBERBIOS BEMOLES" 5 (I, v. 13), el yo poético se detiene en esa parte de la tierra que se encuentra al límite, aferrándose al "insular corazón”, allí, "en la línea mortal del equilibrio" (I, v.16). Imagen que reincide en el poema XII, como aquella "cervical coyuntura", insistencia de instalarse en el margen para recobrar una unidad perdida y no abandonar por completo el origen, que es también hogar.

Esa "línea mortal del equilibrio" corresponde a la zona del pliegue, zona fronteriza donde el sujeto se reconoce: desterritorialización y reterritorialización mediante el influjo de la palabra. Ubicar el lugar donde se coloca el yo poético en el principio y en el final del poemario, evidencia el interés por hablar desde el límite, por situarse en la costa como umbral, allí donde la tierra abre camino

${ }^{2}$ Calabrina o calabrote: que se refiere a un cable grueso que se tira al mar para anclar.

${ }^{3} \mathrm{La}$ arteria hialoidea es una arteria que atraviesa el ojo, cuya función es proporcionar nutrientes para el desarrollo del cristalino durante el periodo fetal. Es importante notar que no presenta ramificaciones.

${ }^{4}$ Grupada es un golpe de aire o de agua impetuoso y violento.

5 Porque además de la inmensidad del mar como manto líquido de la tierra, el sonido que produce su arribo a la costa es de lo más impetuoso y violento a la percepción humana. De ahí que, ante la carencia fonética del lenguaje en relación a los sonidos de la naturaleza (las onomatopeyas, por ejemplo), sea el uso de mayúsculas lo que exprese en el poema esa solemnidad. 
al mar. De esta manera observamos que mientras el poema I hace referencia a la "península impertérrita", el último poema termina con el llamado al agua que cae y que vuelve a comenzar en la profundidad de la tierra: "Canta, lluvia, en la costa aún sin mar" (LXXVII, vv. 18). En este principio y fin no sólo se recupera el escenario náutico, sino el regreso al canto que seguirá a pesar de los embates en la tierra y la crisis de sus límites; para más detalle la última estrofa:

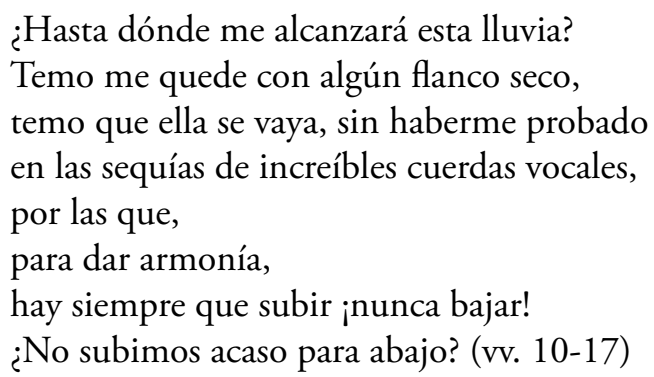

De esta manera, la temporalidad vallejiana se coloca en una línea de "continuo presente" y en una realidad ilógica y discrepante (subir y bajar), pero que paradójicamente no deja de ser canto y armonía. Refiere a un presente desestabilizado por el sujeto moderno que tiene conflictos con su pasado, pero que tira el cabo "a las islas que van quedando". Al respecto, José Vicente Anaya apunta que Vallejo "tiene que convivir con su circunstancia total, y ésta no es lo más favorable para un espíritu entregado a las condiciones del vivir: la aventura humana de hacerse, deshacerse y rehacerse en vida" (Anaya, 1988: 62). 


\section{De los alrededores: correspondencias con La tierra baldía, de T. S. Eliot}

En esta comparativa que surge ante los contextos de 1922 y la publicación de los dos poemarios, Trilce y La tierra baldía, ${ }^{6}$ acudiremos a los cruces existentes y a los temas que preocupan en dichas propuestas estéticas, con la finalidad de mostrar la resolución que cada autor propone y que evidencia la crisis del hombre moderno. En este sentido, para hablar de La tierra baldia consideremos que se trata de un poema de aliento largo que consta de 434 versos, dividido en cinco partes, donde el carácter fragmentario revela un escenario en ruinas, que obliga al hombre a recuperar fuerzas para reconstruir lo devastado: destruir y recrear. En el poema se da cita el monólogo coloquial y la recuperación de la tradición literaria que sustenta al poema: Dante, Shakespeare, Baudelaire, donde un pasado literario cobra importancia por su vigencia como presente simultáneo, de ahí la importancia del empleo del collage con textos de diversas lenguas, de la utilización de técnicas de montaje sincrónico y de acumulación simultánea que enfatizan el hermetismo de la escritura.

Es la primera parte del poema, intitulada "El entierro de los muertos", la que comienza a preguntar sobre la germinación del cadáver muerto en plena primavera. Este yo poético parte de la duda y no deja de cuestionar, a pesar del estado de desolación imperante, que nos recuerda el llamado con el que inicia también Vallejo: "Quién hace tanta bulla":

¿Qué son las raíces que se arraigan, qué ramas crecen

De entre estos escombros pétreos? Hijo del hombre,

No puedes decir, ni imaginar, porque sólo conoces

${ }^{6}$ Para el análisis del poema de T. S. Eliot consideramos la traducción de Jaime Tello, en la edición de Visor, Madrid, 2009. 
Un montón de imágenes rotas, donde el sol palpita, Y el árbol muerto no abriga, el grillo no consuela, Y en la piedra reseca no hay murmullos de agua.

Solamente

Hay sombra bajo esta roca roja,

(Ven bajo la sombra de esta roca roja),

Y te mostraré algo diferente...

Te mostraré el terror en un puñado de polvo (vv. 19-28, 30).

A diferencia del yo poético en el primer poema de Vallejo, observamos que la tierra donde habita el yo poético en La tierra baldía es realmente desoladora, un lugar de escombros pétreos, imágenes rotas y árboles muertos... sin murmullos de agua. Sin embargo, la actitud es la misma: preguntar sobre el fragmento que queda, de la descomposición de la unidad total y de la caída de los grandes relatos; se pregunta acerca del origen, las raíces y lo que crece de esa tierra estéril, pero de una manera irónica, pues ¿qué se puede esperar entonces de los escombros que son incapaces de engendrar vida? Sobre la fatalidad anunciada y la contemplación de las ruinas, María Zambrano refiere que ante dicha situación el argumento se reduce al mínimo "y deja visible en toda su amplitud el horizonte, el tránsito de las cosas de la vida... También las cosas gastadas muestran el paso del tiempo y en el caso de un objeto usado por el hombre algo más: la huella, siempre misteriosa, de una vida humana grabada en su materia" (2007: 235), en un puñado de polvo.

En este caso el pronombre interrogativo que abre la crítica es un "Qué" y no "Quién" — como en Trilce_, porque se sabe a quién se dirige: al hijo del hombre, que puede ser la humanidad entera, y a quien tajantemente confronta y sentencia: "no puedes decir nada, ni imaginar". En este caso no sólo habla del bullicio sino de su incapacidad de nombrar ante la aridez de la tierra. Finalmente, sólo se encuentran las sombras y la fatalidad en la acción que 
promete algo diferente: la muerte. Sin duda alguna, el viso de esperanza queda clausurado en la misma tierra, en su imposibilidad de germinar más que en polvo, pero no sólo por la condición de la tierra sino por la propia existencia, que siente terror y miseria.

Al igual que en Trilce, analicemos el cierre de La tierra baldía, para conocer la solución que ofrece a la crisis del sujeto. Considerando los motivos causales del devenir del hombre moderno, el yo poético se encuentra con el agua — como en Vallejo-, elemento que posibilita la fertilidad de aquellas ruinas pétreas y anuncia:

Yo me senté en la playa

Pescando, con la árida llanura a mis espaldas

¿Pondré al menos mis tierras en orden?...

con estos fragmentos he apuntalado mis ruinas

pues entonces te acomodaré yo. Hyeronimo está otra vez loco.

Datta. Dayadhvam. Damyata.

Shantih shantih shantih

(vv. 424-426, 431-434)

Al dar la espalda a la tierra en busca de la pesca de alimento, la pregunta acerca de la existencia es inminente, pues el yo poético piensa en la idea del orden sobre la tierra que es estéril, sólo grieta y fragmento. Cabe mencionar que se trata del fragmento quinto, "Lo que dijo el trueno", en donde, después de la larga espera de la lluvia y de la ausencia del trueno para dar aviso a su llegada, canta el gallo presagiando el tiempo de fecundación y el inicio de un nuevo día.

Tanto Vallejo como Eliot recurren al llamado de la naturaleza y la vida en su condición primigenia: la de ser agua, el regreso desde las alturas a la tierra. Vallejo invoca el canto de la lluvia y Eliot la voz del rayo: "Datta. Dayadhvam. Damyata", palabras que en sáncrito significan "Da. Compadece. Controla”, enunciación que se coloca "en la costa aún sin mar" como en el verso de Trilce, para 
finalmente decir también en sánscrito "Shantih shantih shantih": "una paz que va más allá de nuestro entendimiento". Se trata del consejo de un dios que habla en el monte a través del trueno y que finalmente nos vuelve a posicionar allí, "en la línea mortal del equilibrio" (I, v. 16), donde es posible hacer de los fragmentos la confrontación directa con las ruinas propias. Pone cara a cara al hombre moderno y su condición fragmentaria, contra la tierra hecha ruinas en sus guerras, pero no para ofrecer el llamado redentor y mesiánico de la salvación y la esperanza ingenua, sino para volver a confiar en la existencia del hombre, más allá de nuestro entendimiento, en el devenir del ser para la muerte.

\section{De los alrededores: la crisis de la existencia y la angustia}

Hablamos de la conciencia histórica del ser que reflexiona sobre la miseria humana y que, como anteriormente se afirmó, incita una confluencia entre temas y necesidades por resolver en una época determinada. En este caso, los vasos comunicantes dialogan y se encuentran en una determinada conciencia histórica donde convergen discursos no sólo poéticos sino también filosóficos. En los poemas que cierran y abren las dos propuestas poéticas observamos una misma preocupación y una duda insistente que se resuelve en el canto que proviene del exterior, del trueno y de la lluvia, que llevan aliento a los parajes yermos de la existencia. La condición del hombre, que se une a un yo poético que pregunta y siente miedo, se enfrenta a la angustia que genera el ser consciente de un estado desolador. Vallejo anuncia un lamento desgarrador ante el sinsentido en el poema XXXIV: "Y se acabó el diminutivo, para / mi mayoría en el dolor sin fin, / y nuestro haber nacido así sin causa" (XXXIV, vv. 14-16).

$\mathrm{Al}$ respecto, un par de décadas después, Octavio Paz explicó el talante de un hombre que despertaba en los albores del siglo XX 
y que estaba lejos de tener en sus manos la cura para el mal de la razón, pues la magia y el mito habían sido desterrados. Paz afirma que:

La historia de la poesía moderna es la de una desmesura. Todos sus grandes protagonistas, después de trazar un signo breve y enigmático, se han estrellado contra la roca. [...] Nacidos casi al mismo tiempo, el pensamiento poético moderno y el movimiento revolucionario se encuentran, al cabo de un siglo y medio de querellas y alianzas efímeras, frente al mismo paisaje: un espacio henchido de objetos, pero deshabitado de futuro (2003: 253, 257).

El problema con el futuro se debe a esa realidad conflictiva con el pasado, con un regreso aparentemente imposibilitado y que entonces hace de la tierra áspera la infértil esperanza de cosechas y remanso. No en vano el sentimiento carcelario en Vallejo, al ver las cuatro paredes en contra de una libertad que se prometió como condición natural al nacer y que ahora clausura al propio cuerpo: "Y sólo yo me voy quedando, / con la diestra, que hace por ambas manos, / en alto, en busca de terciario brazo / que ha de pupilar, entre mi donde y mi cuando / esta mayoría inválida de hombre" (XVIII, vv. 19-23).

La "mayoría inválida de hombre" nos muestra la incertidumbre de la conciencia, sabiéndose un ser para la muerte que canta ante el intento de anclar el cabo a tierra firme. Por ejemplo, el empleo de un lenguaje matemático en la poética trílcica implora el orden dentro del caos y el fragmento, conformando al animal pitagórico que especula sobre la abstracción del ser uno, dos y tres, o cero a la izquierda, “-qué la vamos a haazer-” (IV, v. 8); mientras que en Eliot el hecho de recurrir al collage en lenguas y en personajes de la tradición literaria le permiten modelar el devenir en ruinas. De tal manera que descansan al contemplar su rostro múltiple en una realidad ilógica, unificada en el llamado del agua. 
Esta insistencia en desmantelar una concepción unilateral y personal pone en juego la aparición de un otro que rompe con lo homogéneo y requiere ir en busca de aquél que también existe en el presente, que comparte la angustia y prefiere preguntar, como encontramos en el fragmento "Lo que dijo el trueno" en La tierra baldia: “¿Quién es el tercero que siempre va a tu lado caminando? / ...Deslizándose embozado en una capa parda, / encapuchado / No sé si es hombre o mujer / —Pero ¿quién es ese que camina a tu lado?” (vv. 360-366). En Eliot es más evidente el desmantelamiento, porque recurre a una tradición oriental, allí donde la visión eurocéntrica no ofrece más respuestas; entonces se oye el trueno que habla en sánscrito y que demanda el conocimiento que ofrece la astrología y no la lógica del hombre narcisista. De esta manera el hombre moderno, que no tiene futuro y que es huérfano en la tierra, extiende su sentido hacia renovadas formas, a una tendencia terciaria que rompe los binarismos impuestos por la metafísica y la tradición occidental. ${ }^{7}$

Por ello, la escritura del pliegue no puede reducirse a una mera posición individual, por lo que el registro es colectivo y cultural. Trilce y su devenir de resistencia hacen un llamado al interior de los hombres, a modo de imposición ética que obliga a (re)pensar el sentido de las ataduras sociales, por lo que la crítica a la sociedad

${ }^{7}$ El término de metafísica referido en este contexto responde a las consideraciones de Jacques Derrida en De la gramatología (1986), donde señala que históricamente nuestra sociedad occidental está organizada en pares opuestos, como espíritu y cuerpo, sentido y signo, lo dentro y lo fuera, lo cual es un legado de la metafísica que desde Platón se sustenta entre lo sensible y lo inteligible. Derrida califica este sistema como logocéntrico, cuya repercusión está íntimamente relacionada con el etnocentrismo europeo y occidental, lo cual provoca que el logos se manifieste como extensión mundial de la racionalidad técnica y científica. El logocentrismo nos prohibiría pensar nuestra historia y evolución desde otro punto de vista que no sea el nuestro: la lengua del otro, la cultura del otro y, en general, todas la formas de alteración de una supuesta realidad. 
y los principios del orden y la unidad son simbolizados en lo que Vallejo llama "guardarropía": la imagen del traje, ese traje largo de sentir, que espera a su lavandera del alma. El traje es lo que nos vistió ayer, nos viste todos los días, y representa aquello que nos guarda de la apariencia del exterior, como la máscara que cubre la desnudez de nuestra inocencia. En el poema VI, el yo poético se queja, pero al mismo tiempo justifica y espera "El traje limpio que vestí mañana” (v. 1), planchado de todos los caos, transgrede el tiempo que clausura al presente ante el enfrentamiento con un pasado y un futuro irreconciliables. El designio tiende a hacer una crítica a las apariencias y al presente que multiplica el caos en colectivos (los caos), cuya incertidumbre se acrecienta en la espera de aquella lavandera, que “¡CÓMO NO VA A PODER!” (v. 21) traer el traje limpio de regreso, como una exigencia ética.

Como observamos, la desmesura de la que hablaba Paz se presenta en esta incesante crítica al exterior del ser que es consciente, que se sabe en el "ahí del mundo", y que entonces desmantela los discursos totalizantes de la razón, encarnados en el traje que no es presente, sólo pasado y futuro, y que por lo tanto ahora no puede vestir. Mientras en Vallejo el uso del traje evidencia esta crítica, en Eliot lo hace el juego de ajedrez, que primero abre paso a las confesiones descaradas, pero que de pronto cierra las puertas, debido al uso de las buenas costumbres y las relaciones socialmente correctas, que sólo engañan en un mundo enmascarado que devela la incertidumbre del hombre contestatario.

Sobre el reconocimiento en el otro, sus apariencias y el encuentro con el ser, Heidegger se une a las reflexiones acerca del hombre moderno, en un tema que es recurrente y que muestra las ideas que atañen a los congéneres que comparten un tiempo y un lugar, ya sea desde el discurso poético o filosófico — recordemos pues que $E l$ ser y el tiempo se publica cinco años después que Trilce y La tierra baldía. En este sentido, el filósofo trata sobre el estado de ánimo 
que hace patente la experiencia en el camino, lo que coloca al ser en un lugar y un tiempo. Efectivamente, tanto en Vallejo como Eliot, el canto y la ruina evidencian la desolación del lugar y del tiempo, pero no se trata de un ser para la nada, sino un ser para la muerte. Entonces "Vallejo dice hoy la Muerte está soldando cada / lindero a cada hebra de cabello perdido..." (LV, vv. 3, 4), donde por única vez aparece el yo poético con nombre y actuar: "Vallejo dice". Los versos afirman el "estado de ánimo" del que sabe de la existencia de la muerte, y no sólo eso, la misma Muerte se construye en un presente continuo e inmortal: está soldando esa materia que es también muerte en el cuerpo humano, ese ornamento baldío y estéril, como lo es el cabello perdido.

Reiteradamente es la imagen del cabello la que aparece en el poema LII, donde encontramos la referencia, llamémosla casual, de la palabra "baldío" en Trilce, a propósito de La tierra baldía, cuyos versos son los siguientes: "Y llegas muriendo de risa... le tomas el pelo al pelón decúbito / que hoy otra vez olvida dar los buenos días, esos sus días, buenos con b de baldío, que insisten en salirse al pobre / por la culata de la v / dentilabial que vela en él” (vv. 2534). Se trata de un juego entre palabras y las diferencias entre letras y fonemas, que puesto en el poema, reflexiona sobre el estado de ánimo y la condición del "pelón decúbito" que se encuentra en los días "baldíos", pero no por su carácter inútil, sino por el momento de vela, de vigilia también con la v dentilabial, que nos tensa entre la vida y la muerte. Se trata de una vigilia que torna el "ser ahi”" insufrible para sí mismo, como Heidegger anunciaba. Aunque claro, no todo es grito desolador, pues es más terrible aún reír en ese estado de conciencia, como en el verso anterior, donde uno llega muriendo de risa a la tierra baldía. Sin duda, la ironía y la angustia son una manera de enfrentarse a esta conciencia. Dicha condición recuerda a la tradición romántica de la cual Paz trata en Los hijos del limo, donde escribe: 
La ambigüedad romántica tiene dos modos, en el sentido musical de la palabra: uno se llama ironía y consiste en insertar dentro del orden de la subjetividad la negación de la subjetividad; el otro se llama angustia y consiste en dejar caer, en la plenitud del ser, una gota de nada. La ironía revela la dualidad de lo que parecía uno, la escisión de lo idéntico, el otro lado de la razón: la quiebra del principio de identidad. La angustia muestra que la existencia está vacía, que la vida es muerte, que el cielo es un desierto... (974: $71)$.

La ironía se encuentra en ese yo poético que cínicamente se nombra Vallejo y que habla deliberadamente de la Muerte, condenando los días de vigilia por un pelón decúbito, que una vez más nos da los buenos deseos para llevar la existencia cargada en el hombro. No obstante, en Eliot también aparece este yo poético que, siempre reflexivo, termina con la pregunta que niega la subjetividad de una manera descarada: "Yo recuerdo / Que esas son perlas que sus ojos fueron. / '¿Estás vivo, o no? ¿Es que no tienes nada en la / cabeza?"' (vv. 45-48), pregunta que incita al cambio de escena en el juego de ajedrez, contrariedad puesta en el bar popular, la bohemia, que finalmente desmantela la confrontación de las piezas blancas y negras en la partida, que también es el juego de la vida. El yo poético confronta: ¿qué no tienes nada en la cabeza?, sentencia que demuestra la incapacidad de trascender la angustia existencial.

Resulta significativo ver los cruces entre estas dos propuestas poéticas, donde se parte de la crisis del sujeto y se termina en el "coincidente" canto del agua, en las ruinas donde se deja escuchar el rayo que anuncia el regreso de la vida, a pesar de su condición paupérrima en la tierra, a pesar del salto obligado que provoca que el yo poético penda "en la línea mortal del equilibrio" (I, v. I6). Una vez más, encontramos indicios que abren paso a ciertos vasos comunicantes entre Trilce y La tierra baldia, lo cual no im- 
plica que se hayan leído el uno al otro, pero sí pone en relación las lecturas que preocupan a una generación que ejerce una crítica sobre la tradición occidental, la cual ha dejado al hombre moderno escindido por la instauración de la razón como única vía para el conocimiento.

De esta inconformidad, Vallejo escribe: "Si lloviera esta noche, retiraríame / de aquí a mil años. / Mejor a cien no más. / Como si nada hubiese ocurrido, haría / la cuenta de que vengo todavía" (XXXIII, vv. 1-5). De nuevo, recurre al presente que continúa, en el "vengo todavía" y así será mientras siga en busca de la cura de su existir. Mientras tanto, en Eliot leemos: "Si hubiera agua / Y no hubiera roca / Si hubiera roca / Y también agua / Y agua / Un manantial / Un pozo entre la roca... Pero no hay agua" (vv. 347-353, 359), sólo desolación. Esta incertidumbre es respuesta al "estado de yecto", en palabras de Heidegger; es decir, al momento cuando se asume la conciencia plena de existir ante una angustia inherente: una ética que "busca sugerir la facticidad de la entrega a la responsabilidad" (Heidegger, 2008: 152), porque el hecho de reír o cantar en la tierra baldía implica asumir al mismo tiempo la fatalidad y la convicción ética sobre la condición humana, de su devenir, a pesar de la finitud.

\section{De los alrededores: actitud frente al lenguaje}

Con la finalidad de seguir el camino de lecturas, textos y contextos que convergen temporalmente en un ámbito internacional, ahora en función a la actitud del lenguaje, es pertinente traer a cuenta una generación de críticos que durante 1915 y 1930 se dio a la tarea de abordar las cualidades intrínsecas del arte literario. El formalismo ruso surge, de acuerdo con Roman Jakobson, en la época en que jóvenes experimentadores en las artes y en las ciencias promovieron la lingüística y la poética en el análisis del aspecto 
creador del lenguaje, para postular el cambio esencial que opera en el lenguaje poético, a través de la relación entre el significante y el significado. Además de la importancia que resultó para el estudio de la literatura dejar a un lado los comentarios psicologistas y biográficos en el análisis de una obra, el formalismo y esta nueva posición frente al lenguaje, y por lo tanto ante el arte y la misma existencia, está estrechamente vinculada en sus comienzos con la vanguardia artística de la época. Sin embargo, en el análisis literario la actitud hasta entonces artística se torna científica de ahí en adelante.

Este contexto dará pie a la crisis del sujeto moderno que apela a su condición racional y lógica, por lo que la poesía salvaría su estimulante caos en la vanguardia con un Altazor (1919), por ejemplo, donde se desmantela el lenguaje en sus unidades mínimas de significación, en aquello irracional y mágico que también explica al hombre. Sobre este desmantelamiento a las oposiciones binarias y conceptos fundamentales de la metafísica y su tradición eurocéntrica, así como a los propios conceptos de forma y estructura, es hasta la década de los sesenta cuando el enfoque crítico de la deconstrucción, a nombre de Jacques Derrida, niega la posibilidad de la denotación pura, defendiendo la autonomía del signo respecto a los significados trascendentales y a la detección de fenómenos marginales reprimidos por un discurso hegemónico. Por supuesto que esta crítica sólo podía surgir bajo los antecedentes formalistas propuestos en la década de los veinte, de otra manera no existiría asidero para plantear la disociación del signo y así proponer una subversiva puesta en escena del signo lingüístico, como veremos más adelante en Trilce.

El vaso comunicante con este lineamiento teórico es el término "deconstrucción", traducción que Derrida propone del término alemán Destruktion, que Heidegger habría de emplear en $E l$ ser y tiempo para evidenciar que la experiencia del ser en el tiempo se 
encontraba recubierta por la terminología de la metafísica occidental. Con este antecedente, Derrida postula que la gramatología posibilita la liberación de la escritura dominada por la metáfora, la metafísica y la teología. Con estos principios, el deconstructivismo exige lecturas subversivas y no dogmáticas de los textos (de todo tipo) como acto de descentralización, que darán una significación diferente de lo que parecían estar diciéndonos. El motivo central de deconstruir la metafísica es abrir un nuevo acercamiento a la pregunta más radical que se pueda hacer sobre el pensamiento humano: el cuestionamiento del sentido del ser. Para ello es necesario detener nuestra pre-comprensión o pre-entendimiento de lo que significa la humanidad para ir más allá del pensamiento occidental, que está caracterizado por un imperialismo y un etnocentrismo histórico. Para Derrida, se trata de un intento de ver lo que somos desde el otro lado del borde.

En Trilce esta crisis del lenguaje es evidente, pues hay una intencionalidad de borrar precisamente la relación directa con el referente de una realidad caótica, elemento que, según Jean Franco (1984: 577), marca el carácter "hermético" de los poemas. La oscuridad de los poemas nace del esfuerzo por expresar niveles de la realidad en los que nada es claro o es "Lomismo". Se trata pues de desentrañar mecanismos que crean la presencia de esos movimientos de la conciencia, del ser que se sabe en el mundo y su devenir, y que expone su resistencia a una organización racional y totalizante. Sobre estos esfuerzos desafiantes, Derrida afirma que necesariamente "son discretos y dispersos, casi imperceptibles: ello pertenece a su sentido y a la naturaleza del medio en el que producen su operación" (1986: 9).

Ante esta operación, la apuesta por exponer el cambio que mueve en las relaciones entre el significante y el significado, se manifiesta en Trilce en el inefable término del acto sexual que encuentra su referente en la palabra, a través no sólo de la unión de 
referentes distintos y contradictorios, sino de su puesta en el espejo, donde el inicio ahora es el fin y viceversa: "odumodneurtse", al estruendo-mudo, una evidente deconstrucción. La creación demuestra la artificialidad del lenguaje y su función en la poesía, a través de la necesidad de nombrar lo inefable, aquello que escapa a la lógica humana, pero que intuye. Así, sucede un acto sexual en el acto fonético, donde la grafía $v$ es la que trasgrede su relación con el referente del sexo femenino; es decir, con la presencia de la mujer, de lo otro, lo que atiende al artificio que recrea al lenguaje una vez más:

Vusco volvvver de golpe el golpe.

Sus dos hojas anchas, su válvula

que se abre en suculenta recepción

de multiplicando a multiplicador,

su condición excelente para el placer,

todo avía verdad

(IX, vv. I-6)

Esta relación de grafías va más allá de los contornos de la $v$, pues entonces contraviene la misma ortografía con el uso de vusco, avía y vaveo, y la repetición de la misma letra en volvvver, enfatizando la cadena sintagmática con palabras como válvula y verdad, que no sólo funcionan por su carga semántica, sino por su relación que desestabiliza las demás enunciaciones. Esta exploración de relaciones entre grafías y sus referentes nos recuerda a los versos antes citados, donde la $b$ de $b$ uenos días amplía su significación a la $b$ de $b$ aldío, pero que con la $v$ dentilabial establece el estado de vigilia que condiciona el propio devenir del sujeto. Así, el uso del lenguaje científico y objetivo en Vallejo, que comprende los números, neologismos y otros términos abstractos como las coordenadas espaciales y temporales en las conjugaciones o declinaciones, tiene más bien el objetivo de desmantelar las posibles referencias genera- 
das por la estructura lógica de la escritura y de desafiar al término de la verdad que se encuentra en este acto. Además de considerar, por ejemplo, el título de los poemas que no se ofrecen como un paratexto que dé indicios sobre el contenido, los cuales no siguen orden cronológico ni temático, donde encontramos una clara ruptura y fragmentación en el propio poemario.

En este sentido, el proyecto crítico postulado por Derrida fue practicado por Vallejo desde la poesía y décadas anteriores, al deconstruir el concepto de la palabra en una realidad donde la fonética de la escritura debe disimular su propia historia en el acto de su producción: en Trilce no hay disimulo sino fuga y transgresión, la grafía confronta al fonema, al propio significante. Vallejo era un gran conocedor de los mecanismos de ritmo y métrica en lengua española, lo que le permitió realizar una cuidadosa deconstrucción de una poética anterior, modernista y clásica, dislocando la sintaxis, cambiando funciones y categorías gramaticales, nominalizando adjetivos o verbos, con la finalidad de proyectar su propia concepción de la realidad. Su realidad es una oposición al orden establecido —es ilógica y absurda—, que se evidencia en el poema XIV:

Cual mi explicación.

Esto me lacera de tempranía.

Esa manera de caminar por los trapecios. ${ }^{8}$

Esos corajosos brutos como postizos.

Esa goma que pega el azogue al adentro.

Esas posaderas sentadas para arriba.

Ese no puede ser, sido.

Absurdo.

${ }^{8}$ Los "trapecios" pueden referir al hueso de la mano, en la sección del carpo llamada comúnmente "muñeca", lo que en el verso recrearía la imagen de caminar literalmente de cabeza, es decir caminar con los trapecios: oposición absoluta a la lógica establecida del verbo "caminar". 


\section{Demencia.}

Pero he venido de Trujillo a Lima.

Pero gano un sueldo de cinco soles. (vv. 1-11)

Ante la falta de explicación de la realidad, Vallejo impacta la gramática y la sintaxis, por lo que el poema carece de soporte explicativo. Véase el primer verso, donde la elisión del verbo principal nos lleva a la enumeración de oraciones subordinadas, marcadas por el ritmo del pronombre demostrativo en sus diversas formas: esto, eso, esos, esa, ese; cadencia que se pierde en el "Absurdo" y en la "Demencia", para instalarnos en la conjunción adversativa que anuncia la acción: "Pero he venido desde Trujillo a Lima" (v. 10) para obtener una aberración por salario. Esa realidad absurda es a la que Vallejo desafía y transgrede. Sin embargo, la transgresión tiene consecuencias que el yo poético asume: "Esto me lacera de tempranía" (v. 2), tiempo que nuevamente muestra la incertidumbre ante la existencia y la angustia en su propia nominalización.

En el poema vemos las contradicciones manifiestas de la vida misma, al encontrarnos binarismos metafísicos volcados, imágenes ilógicas en un mundo puesto al revés: "Esas posaderas sentadas para arriba" (v. 6). La trangresión del signo lingüístico en "Ese no puede ser, sido" (v. 7) vuelve vigente el acto de rebelión y resistencia, donde la palabra se convierte en intersticio para producir una fuga de sonoridad y de semántica absurda. De esta manera, el poeta transgrede — "Cual mi explicación" (v. 1) — las formas gramaticales, fonéticas y sintácticas en tanto elementos que sirven para reflejar que los acontecimiento vivienciales no corresponden al orden que impone el uso racional del lenguaje. Logra desmantelar el prejuicio metafísico propuesto por Derrida, que provocaba la inaccesibilidad a nosotros mismos y a lo que queremos decir, mediante el desafío al tiempo y a las huellas o rastros de las palabras. En el poema Vallejo le da un significado distinto - nuevo- a la escritura, a los elementos materiales (fonéticos y gráficos) que se 
distinguen entre sí para crear una propia significación mediante la transgresión del signo lingüístico.

Para ello, el uso de la ironía contribuye al cambio de sentido y lo confronta, siendo una suerte de libertad y autonomía, "como el salto por el ojo de la aguja!" (XXXVI, v. 26). Este movimiento funciona como eje de una dialéctica audaz, que lleva al extravío, a lo inédito. Una invención que en Vallejo culmina con el canto fatal de la conciencia, donde a pesar de todo "Canta, lluvia". Es en esta intención donde Trilce suena a juego, absurdo y ritmo, puesto que hay una transgresión a los binarismos y fundamentalismo de occidente, para ofrecer una fuga radical a los discursos hegemónicos.

\section{Consideraciones finales}

La propuesta de análisis que guió el presente ensayo tuvo como finalidad realizar un acercamiento al poemario Trilce, de César Vallejo, a partir de su relación con otras lecturas, donde se advirtieron los vasos comunicantes que exponen las preocupaciones del hombre y sus congéneres. En los albores del siglo XX, la actitud del hombre moderno comienza a cuestionar los grandes discursos impuestos por la lógica y la razón, bajo una tradición que hizo de la metafísica el único camino de conocimiento acerca del ser. El hombre, ubicado en Francia, Inglaterra, Alemania o Perú, emprende el camino que lo lleva a desestabilizar los presupuestos que lo han dejado varado y escindido ante la angustia por su devenir.

Asuntos como la crisis del lenguaje, la angustia por la finitud y la búsqueda de una cura que posibilite el canto evidencian la fatalidad de una generación que reflexiona sobre los inicios de una primera guerra mundial y, por lo tanto, de la desilusión y desengańo de la racionalidad. Este estado de ánimo asumido, que en el caso de Trilce y La tierra baldía, coincide en un hermetismo evidente; no debe confundirse con un estado perjudicial y nocivo, pues 
reclama una conciencia ética que se sabe insufrible pero también valiente, que confronta su realidad fragmentaria en las mismas ruinas en las que habita.

De esta manera, el encuentro de discursos poéticos y filosóficos en 1992 revela la condición humana y su correspondencia con las propuestas que surgen en el artificio del lenguaje, lugar que permite el hallazgo de un ser que se destruye, construye, encuentra y descubre, huérfano y en la incertidumbre, pero capaz de confesarse en el canto de la lluvia, de develarse en el acto poético.

\section{Bibliografía}

Anaya, José Vicente, 1988, “César Vallejo, corazón tiesto regado de amargura. La poesía del sufrimiento humano", en Evodio Escalante (sel. y notas), César Vallejo. La perspectiva ausente, México, UAM, pp. 62-70.

Derrida, Jacques, 1986, De la gramatología, 4a ed., Óscar del Barco y Conrado Ceretti (trads.), México, Siglo XXI.

Eliot, T. S., 2009, La tierra estéril, Jaime Tello (trad.), Madrid, Visor.

Ferrari, Américo, 1996, "Nota filológica preliminar" y "Trilce”, en César Vallejo, Obra poética, $2^{\mathrm{a}}$ ed., Américo Ferrari (coord.), México, ALLCA XX / FCE, Col. Archivos, pp. XXXIII-XLI y 161-169.

Franco, Jean, 1996, "La temática de Los heraldos negros a Poemas póstumos", en César Vallejo, Obra poética, $2^{\mathrm{a}}$ ed., Américo Ferrari (coord.), México, ALLCA XX / FCE, Col. Archivos, pp. 575-605.

Heidegger, Martin, 2006, Arte y poesía, 2a ed., Samuel Ramos (prol. y trad.), México, FCE.

,2008, El ser y el tiempo, México, FCE. 
Jakobson, Roman, 2007, "Hacia una ciencia del arte poético", en Tzvetan Todorov (comp.), Teoría de la literatura de los formalistas rusos, $11^{\text {a }}$ ed., Siglo XXI, México, pp. 71-80.

Oviedo, José Miguel, 1996, "Los heraldos negros", en César Vallejo, Obra poética, $2^{\text {a }}$ ed., Américo Ferrari (coord.), México, ALLCA XX / FCE, Col. Archivos, pp. 1-17.

Paz, Octavio, 1974, Los hijos del limo, Barcelona, Seix Barral. ,2003, El arco y la lira, México, FCE.

Todorov, Tzvetan, 2007, Teoría de la literatura de los formalistas rusos, $11^{\text {a }}$ ed., México, Siglo XXI.

Vallejo, César, 1996, Obra poética, $2^{\mathrm{a}}$ ed., Américo Ferrari (coord.), México, ALLCA XX / FCE, Col. Archivos.

tedra. , 2003, Trilce, 5a ed., Julio Ortega (pres.), Madrid, Cá-

Valente, José Ángel, 1996, "Liminar: César Vallejo o la proximidad”, en César Vallejo, Obra poética, edición crítica, Américo Ferrari (coord.), México, ALLCA XX / FCE, Col. Archivos, pp. XXIII-XXVI.

Zambrano, María, 2007, El hombre y lo divino, Madrid, FCE, Col. Heteroclásica, pp. 370. 